\title{
ESPIRITUALIDADE E SAÚDE: UMA EXPERIÊNCIA NA GRADUAÇÃO EM MEDICINA E ENFERMAGEM
}

\author{
SPIRITUALITY AND HEALTH: AN EXPERIENCE IN UNDERGRADUATE SCHOOLS OF MEDICINE \\ AND NURSING
}

ESPIRITUALIDAD Y SALUD: UNA EXPERIENCIA EN LA GRADUACIÓN EN MEDICINA Y ENFERMERÍA

\author{
Valdir Reginato ${ }^{1}$ \\ Maria Auxiliadora Craice De Benedetto ${ }^{2}$ \\ Dante Marcello Claramonte Gallian ${ }^{3}$
}

Resumo Pesquisas demonstram que, ainda hoje, a espiritualidade representa um aspecto importante na vida humana. As conquistas do modelo biomecânico de ensino e prática da medicina não conseguiram ofuscar o papel que a espiritualidade ocupa no processo saúde-doença. Seguindo uma tendência que ocorre em escolas médicas de todo o mundo, os autores introduziram, na Universidade Federal de São Paulo, a disciplina eletiva - Espiritualidade e Medicina - dirigida a estudantes de medicina e enfermagem com o objetivo de promover o reconhecimento da dimensão espiritual do paciente e, consequentemente, um atendimento mais humanizado. Após quatro anos de curso, procedeu-se a um estudo qualitativo para determinar o perfil dos estudantes que escolheram a disciplina eletiva, sua percepção em relação ao tema espiritualidade e saúde e a importância atribuída ao curso no que concerne à sua formação pessoal, profissional e humanística. Os textos produzidos pelos alunos durante o curso constituíram a principal fonte de dados. A interpretação dos dados foi realizada por meio de um enfoque da fenomenologia hermenêutica e evidenciou os seguintes temas: busca de sentido da vida; independência entre concepções acerca de Deus e espiritualidade e a importância atribuída à disciplina; espiritualidade e humanização; e espiritualidade, cuidado de si e autoconhecimento.

Palavras-chave espiritualidade e saúde; educação em saúde; humanização.
Abstract Research shows that, today, spirituality is an important aspect of human life. The achievements made by the biomechanical model of teaching and practice of medicine were unable to overshadow the role that spirituality plays in the health-disease process. Following a trend occurring in medical schools throughout the world, the authors introduced at the Federal University of São Paulo the optional Spirituality and Medicine class, aimed at medical and nursing students and to promote the recognition of the spiritual dimension of the patient and, thus, afford more humane care. After four years of the course being offered, a qualitative study was carried out to determine the profile of the students who chose to take the class, their perception concerning the spirituality and health topic, and the importance attributed to the course when it comes to their personal, professional, and humanistic development. The texts produced by the students during the course were the main source of data. The data were interpreted through a hermeneutic phenomenology focus and highlighted the following issues: The search for the meaning of life; independence of views about God and spirituality and the importance given to the discipline; Spirituality and humanization, and spirituality, self-care and self-knowledge. Keywords Spirituality and health; health education; humanization. 


\section{O lugar da espiritualidade na saúde}

A identificação dos 'primeiros médicos' confunde-se, na História, com a figura de sacerdotes, xamãs e curandeiros, e isto fica claro quando verificamos que os males do corpo eram principalmente relacionados à interferência de deuses e situações místicas incompreensíveis no mundo natural. Mesmo com o desenvolvimento da ciência, ainda se manteve um vínculo entre a cura do corpo e a condição de crença do paciente em um campo sobrenatural em que, mediante a sua fé ou a intercessão de orações e cultos, o paciente poderia encontrar a saúde, principalmente quando esgotados todos os recursos conhecidos (Lopes, 1970).

Muito recentemente, no século XX, o desenvolvimento tecnológico acelerado favoreceu o acesso a uma visão microscópica da doença e propiciou uma leitura bioquímica dos fenômenos, o que conduziu, no campo da saúde, a uma reinterpretação dos mecanismos fisiopatológicos. A partir do século XVI, com o incremento de instrumentos que possibilitaram uma visão mais ampla e, ao mesmo tempo, fragmentada do ser humano, a abordagem do processo saúde-doença passou a ser analisada basicamente dentro de uma avaliação do 'desequilíbrio bioquímico', em que, por meio da ação de fármacos cada vez mais específicos, poderíamos promover a homeostase necessária ao organismo. Mesmo a ideia do 'terreno favorável de predisposição' em relação às doenças infecciosas foi minimizada, ao passo que o poder da vacinação e o emprego dos antibióticos ganhavam cada vez mais força para controlar o crescimento de agentes nocivos, procedimentos esses com ações conhecidas no campo biomolecular (Gallian e Reginato, 2009; De Marco, 2003; Drane e Pessini, 2005).

Neste contexto de busca pelo sucesso terapêutico baseado na linguagem bioquímica da vida, cuja ação oferecida por drogas específicas e, mais recentemente, por possíveis interferências nos mecanismos envolvendo o próprio código genético, tendeu-se à marginalização da ação do 'sobrenatural' ou de qualquer outro elemento relacionado à transcendência como fator de influência no processo de cura. Entretanto, apesar de a pesquisa científica, por longas décadas, ter mantido um silêncio a esse respeito, para uma boa parcela dos pacientes nunca deixou de existir a consciência da participação desse elemento misterioso, imponderável, não quantificável pela metodologia científica, que é a condição da fé, descrita por Sir William Osler em seu artigo clássico - The faith that heals. Advertia o autor acerca da necessidade de o clínico estar atento a esta 'força poderosa' presente nos pacientes (Osler, 1910).

Nos EUA, uma pesquisa feita pelo Instituto Gallup mostrou que $80 \%$ dos americanos diziam que a frase "eu recebo bastante conforto e apoio de minhas crenças religiosas" era verdadeira, e que, a partir dos 65 anos, 
esta porcentagem subiu para 87\%. Mais recentemente, Koenig (2005) verificou que $90 \%$ dos pacientes dizem que crenças religiosas e suas práticas são importantes formas pelas quais eles podem enfrentar e melhor aceitar suas doenças físicas e mais de $40 \%$ indicam que a religião é o fator mais importante que os ajuda nessas horas. Assim, observa-se uma reavaliação da influência da espiritualidade nas condições de vida cotidiana, incluindo-se a sua participação no processo saúde-doença (Guimarães e Avezum, 2007; Yawar, 2001).

A Association of American Medical Colleges reconhece que a espiritualidade é um fator que contribui para a saúde de muitas pessoas. O conceito de espiritualidade é encontrado em todas as culturas e sociedades. Ela é expressa nas buscas individuais para um sentido último por meio da participação na religião e crença em Deus, família, naturalismo, racionalismo, humanismo e, até mesmo, nas artes. Todos esses fatores podem influenciar na maneira como os pacientes e os profissionais da saúde percebem a saúde e a doença e como eles interagem uns com os outros. Por esse motivo, a Association of American Medical Colleges defende que uma educação adequada na área da espiritualidade é fundamental na formação dos acadêmicos de medicina e recomenda que os estudantes sejam advertidos que espiritualidade e crenças culturais e suas práticas são elementos importantes para a saúde e o bem-estar de muitos pacientes. Assim, a espiritualidade e crenças culturais e suas práticas deverão ser incorporadas dentro do contexto dos cuidados dos pacientes em uma variedade de situações clínicas já na formação acadêmica. Dessa forma, os futuros profissionais de saúde reconhecerão que sua própria espiritualidade, crenças e práticas poderão afetar os caminhos de relacionamento e cuidados com os pacientes (Puchalski, 2001).

\section{A espiritualidade no ensino médico}

Essas referências, que a cada ano recebem novos reforços pela grande quantidade de trabalhos que têm sido publicados na literatura científica em língua inglesa, incentivaram as escolas médicas a introduzir em sua grade curricular disciplinas dirigidas ao tema da espiritualidade. Há menos de vinte anos eram poucas as faculdades de medicina norte-americanas que apresentavam essa disciplina em seus currículos. Atualmente, mais de cem das 125 escolas médicas incluíram o conteúdo de espiritualidade em suas grades curriculares. Além disso, torna-se cada vez mais frequente a importância dada a este tema entre a classe médica (Savioli, 2006; Larimore, 2001).

Segundo Puchalski (2001), diversas associações norte-americanas têm reconhecido a necessidade da valorização do ensino da espiritualidade na formação do médico. De acordo com The Joint Commission on Accreditation 
of Healthcare Organizations, o cuidado pastoral ou de outros serviços espirituais são considerados parte integrante dos cuidados de saúde e da vida diária para muitos pacientes. Assim, o hospital deverá estar capacitado para prover esses cuidados para pacientes que o desejarem. O tema espiritualidade costuma emergir fortemente nas fases de terminalidade, tanto para os pacientes quanto para seus familiares. The American College of Physicians recomenda que ao final da vida os médicos estendam seus cuidados para atender aos pacientes em seu sofrimento psicossocial, existencial e espiritual. Segundo a Association of American Medical Colleges, é necessário que médicos mantenham empatia e compaixão, procurando buscar compreender o significado das histórias dos pacientes em um contexto amplo de crenças e valores familiares e culturais. Somente assim serão capazes de continuar cuidando dos pacientes moribundos considerados fora de possibilidades terapêuticas.

Puchalski (2001) refere ainda que a Association of American Medical Colleges recomenda um currículo de espiritualidade para escolas médicas com objetivos específicos, sugerindo que os estudantes de medicina tenham habilidade em fazer uma 'história espiritual', em que se compreenda a dimensão espiritual do paciente, se há qualquer relação com o processo de adoecer dele, assim como se ele se utiliza de sua crença como instrumento de esperança para a terapia, valendo-se de seus orientadores espirituais. A Associação considera que a questão da espiritualidade na vida pessoal dos estudantes possa promover seu melhor desenvolvimento profissional.

Neste panorama, fica clara a necessidade de se preparar os estudantes da área de saúde a melhor acolher os pacientes que muitas vezes apresentam seu sofrimento por meio de uma linguagem que lhes é indecifrável. Para tal, urge a criação de cenários didáticos que propiciem a discussão de temas que ampliem a visão dos estudantes para além do modelo biomecânico, o que inclui o campo da espiritualidade.

A dimensão da espiritualidade, mais do que acrescentar um novo conhecimento, é uma maneira de ver o universo dos acontecimentos numa nova perspectiva, outrora reduzida a uma visão tecnicista, em que uma abertura para a reflexão sobre questões essenciais e existenciais passa a ocorrer. A dimensão da espiritualidade diz respeito a um plano metafísico que não se limita a qualquer tipo de crença ou prática religiosa. Nela é contemplado o conjunto de emoções e convicções de natureza não material, os quais nos remetem a questões como o significado e o sentido da vida (Volcan, 2003). Assim, a espiritualidade não está vinculada necessariamente a uma fé religiosa em uma divindade específica. Na verdade, o ser humano é intrinsecamente espiritual, uma vez que tem a capacidade de autoconsciência, reflexão sobre si e autotranscendência (Salgueiro e Goldim, 2007).

Para Monteiro (2008), a espiritualidade corresponde à abertura da consciência ao significado e totalidade da vida, abertura essa que possibilita uma 
recapitulação qualitativa do processo vital. A busca de sentido ou significado para a vida envolve uma necessidade que somente pode realizar-se em um nível imaginário e simbólico.

Lidar com a dimensão espiritual do ser humano em um mundo dominado pela fragmentação e tecnologia não é uma coisa fácil. Mas é também um tema instigante, o qual estimulou a criação, em 2007, na Universidade Federal de São Paulo (Unifesp) - Escolas Paulista de Medicina e Paulista de Enfermagem - a disciplina eletiva Espiritualidade e Medicina dirigida a estudantes de graduação da medicina e enfermagem (entre $3^{\circ}$ e $8^{\circ}$ semestres). O curso tem carga horária de 32 horas, distribuídas em aulas teóricas e seminários ao longo de oito encontros semanais de quatro horas. O programa compreende desde o questionamento reflexivo sobre o porquê estudar espiritualidade na área da saúde até a influência desta nos resultados terapêuticos (incluindo riscos e benefícios) e na promoção de uma assistência mais humanizada. Inclui estudos sobre as grandes religiões, anamnese espiritual, reflexões sobre Deus, fé, dor e sofrimento, morte e questões bioéticas e discussões acerca da transcendência enquanto um campo a ser explorado dentro dos domínios da pesquisa científica e suas limitações metodológicas. O objetivo desta disciplina é levar a uma reflexão que favoreça, ao término do curso, o estudante a perceber a importância da espiritualidade como fator de influência no acompanhamento do paciente no processo saúde-doença e sua participação como instrumento de humanização no atendimento (Pinto e Pais-Ribeiro, 2007; Saad, Masiero e Battistella, 2001; Gallian, 2000).

\section{Objetivos do estudo e metodologia}

O objetivo do estudo foi apresentar o perfil dos estudantes que escolheram a disciplina eletiva Espiritualidade e Medicina, especialmente no que diz respeito a questões ligadas à espiritualidade e religiosidade, e verificar, por meio de métodos qualitativos, a percepção dos estudantes de medicina e enfermagem em relação ao tema espiritualidade e saúde e a importância atribuída ao curso no que concerne à sua formação pessoal, profissional e humanística.

A avaliação foi realizada por um período de quatro anos (2007-2010), em que 114 estudantes da graduação de medicina e enfermagem (entre o $3^{\circ}$ e $8^{\circ}$ semestres) completaram a disciplina eletiva Espiritualidade e Medicina na Unifesp.

Ao início do curso, buscou-se determinar o perfil dos estudantes que frequentaram a disciplina no que diz respeito à identidade de crença pessoal, participação em atividades religiosas, ao conceito de espiritualidade e de Deus e à importância atribuída a Deus e à espiritualidade em suas vidas. 
Para tal, os graduandos responderam a um questionário com questões fechadas de múltipla escolha e questões abertas e a mais vinte assertivas sobre espiritualidade e saúde para que concordassem ou não. Certamente, é de suma importância conhecer-se quem são as pessoas a quem é direcionado um curso, pois a forma escolhida para se transmitir determinado conteúdo deverá, certamente, adequar-se às características do grupo.

Ao término do curso, completaram outro questionário com questões de múltipla escolha em que avaliaram o grau de satisfação em relação ao curso, importância para a formação pessoal e profissional, interesse em linha de pesquisa e recomendação do curso para novos colegas.

A título de avaliação de captação do conteúdo apreendido, os estudantes foram solicitados, ao final do curso, a analisar situações clínicas, de acordo com a ótica da espiritualidade. A avaliação foi realizada sob a forma de dissertação individual. Além disso, os estudantes foram orientados a escrever um relatório pessoal de avaliação do curso também no formato de dissertação individual.

As respostas às questões fechadas de múltipla escolha e de concordância ou não concordância às assertivas foram empregadas para a determinação do perfil dos estudantes.

As dissertações e respostas às questões abertas geraram textos que foram interpretados por meio de métodos qualitativos de acordo com o estilo de organização denominado imersão/cristalização (I/C), o qual é inspirado na fenomenologia hermenêutica (Borkan, 1999). Optou-se por métodos qualitativos, pois estamos buscando significados, variações e experiências perceptuais de um fenômeno para, dessa forma, capturar suas naturezas holísticas ou interconectadas. Os métodos qualitativos permitem a ampliação do conhecimento em relação a um determinado fenômeno. São adequados, por exemplo, para avaliar uma intervenção em um contexto específico, sem nenhuma expectativa imediata para generalização e, sim, para descobrir ou acompanhar as consequências sistêmicas de mudanças ou intervenções (Kuzel, 1999). A fenomenologia hermenêutica é uma metodologia interpretativa que se desenvolveu graças à combinação de ambas de acordo com a visão de Heidegger e Gadamer (Boyd, 1990).

A fenomenologia é um movimento filosófico fundamentado no pensamento do filósofo e matemático Husserl, cuja principal obra foi publicada em 1931. Representou uma resposta aos anseios de pesquisadores que consideraram o método científico vigente insuficiente para o estudo da experiência humana, pois este as reduziria a um pequeno número de conceitos. Busca o entendimento das experiências vividas por indivíduos em seu cotidiano, estudadas através de contato sustentado com pessoas em seu ambiente pessoal (Boyd, 1990). A fenomenologia é o estudo daquilo que se mostra. Representa, portanto, a ciência da experiência. Estuda o processo pelo qual 
tudo o que é informado pelos sentidos é alterado em uma experiência da consciência. Permite a geração de dados ricos e descritivos (Reale, 1991).

A hermenêutica, que no passado compreendia regras organizadas para a interpretação de textos (Reale, 1991), foi se expandindo como um ramo de conhecimento à condição de fundamento epistemológico de todo o conhecimento dos fenômenos humanos para, enfim, atingir uma dimensão filosófica. Esta é caracterizada por uma discussão metadiscursiva que se funde na linguagem e compreensão não apenas das obras humanas, mas também das próprias realidades humanas (Ayres, 2005).

A fenomenologia hermenêutica propicia a interpretação de fenômenos conforme aparecem em texto ou palavra escrita e representa a base da pesquisa qualitativa. O estilo de interpretação denominado imersão/cristalização escolhido para este estudo é totalmente congruente com as técnicas interpretativas da fenomenologia hermenêutica. Seu processo básico consiste em ler, reler e imergir profundamente nos dados até que insights se cristalizem e venham à tona. Esta imersão profunda nos dados implica vivenciar e experimentar as experiências descritas. Este processo exige do pesquisador reflexividade, ou seja, autoconhecimento e profunda reflexão, para que possa detectar suas próprias influências nos achados e interpretações (Borkan, 1999).

Reflexividade requer uma consciência da contribuição do pesquisador para a construção de significados ao longo do processo de investigação e um reconhecimento da impossibilidade de permanecer fora da questão pesquisada durante a realização da pesquisa. Reflexividade, então, exorta-nos a explorar as formas pelas quais a participação de um pesquisador em um estudo particular influencia, age e informa sobre tal investigação (Nightingale e Cromby, 1999).

As descobertas ou temas emergentes em I/C devem se abordadas de forma contemplativa, como em um processo de criação artística. Todo o conhecimento e experiência do pesquisador devem servir como um fio condutor que organiza os temas cristalizados. Aqui, o todo é muito mais do que a soma das partes e os temas identificados devem ser organizados de forma compreensível. Dessa forma, a interpretação do significado é caracterizada pelo círculo hermenêutico, ou seja, o entendimento de um texto acontece por meio de um processo no qual o significado das partes separadas é determinado pelo significado global do texto, que, por seu turno, pode alterar o significado das partes, e assim sucessivamente. Na tradição hermenêutica, essa circularidade não é vista como um círculo vicioso, porém muito mais como um círculo frutífero, uma espiral, o que implica a possibilidade de um aprofundamento e um entendimento contínuo do significado (Borkan, 1999).

Assim, emergiram alguns temas predominantes que foram trabalhados de acordo com a perspectiva dos autores que, além de se focarem nos textos compostos pelos graduandos durante a disciplina, atuaram, durante toda a experiência didática, como observadores participantes. 


\section{A percepção dos estudantes quanto à espiritualidade na formação pessoal e profissional}

$\mathrm{O}$ perfil dos estudantes refere-se às principais características daqueles que optaram pela disciplina eletiva Espiritualidade e Saúde e as suas opiniões acerca de religião, espiritualidade, Deus e o curso.

Nos quatro anos, (2007 a 2010), o curso contou em média com trinta alunos inscritos a cada ano (número máximo de vagas para uma eletiva na Unifesp). Deve-se advertir que estes grupos apresentavam algumas peculiaridades, uma vez que a maior parte dos alunos optou por fazer a disciplina espontaneamente dentro de um universo de trinta disciplinas eletivas a serem escolhidas. Assim, não se pode considerá-los como representativos do universo dos alunos na faculdade e sim apenas avaliar o interesse dos que optaram por cursá-la.

No primeiro ano, o curso foi oferecido somente a estudantes de medicina e no último, a participação predominante foi de estudantes de enfermagem. Nos demais anos, ocorreu uma equivalência entre os graduandos de medicina e enfermagem. Dentre os graduandos de medicina, houve um equilíbrio de distribuição entre os sexos. Em relação à enfermagem, todas as participantes foram do sexo feminino. A desistência não foi significativa. Convém lembrar que as inscrições são feitas por ordem de chegada, não sendo reservadas vagas em igual número para a medicina e enfermagem.

A maioria dos participantes declarou uma religião, cerca de $1 / 5$ apontou para o agnosticismo (acreditam em Deus, mas desvinculado de qualquer crença religiosa) e uma pequena minoria declarou ateísmo. O agnosticismo e ateísmo predominaram entre os graduandos de medicina, especialmente naqueles de sexo masculino. No entanto, comparando-se as estudantes de medicina e enfermagem, verificou-se um percentual mais elevado de ateísmo ou agnosticismo entre as primeiras.

A maioria dos participantes também atribuiu importância à presença de Deus em suas vidas, em uma porcentagem semelhante aos que declararam uma crença religiosa e aos que, dentro de um universo de trinta disciplinas oferecidas, escolheram a disciplina Espiritualidade e Saúde como primeira ou segunda opção. Estes representaram a grande maioria, especialmente entre as estudantes de enfermagem.

Metade do grupo referiu participação habitual na prática religiosa relacionada a suas crenças, enquanto os demais posicionaram-se como não participativos ou esporádicos. Houve uma tendência a maior participação da religiosidade no grupo da enfermagem em relação ao de medicina.

Quanto ao conceito de Deus, as manifestações variaram desde em não acreditar em nada até a um conceito amplo e complexo, muitas vezes pertinente a crenças religiosas, que incluía ideias como: paternidade divina, Ser 
milagroso, Ser de conforto, Criador de tudo, que está em tudo e em todos. A relação de Deus com energia foi comumente mencionada e, considerando-se ambos os grupos, a crença de Deus como 'Criador de tudo' predominou em relação à ideia de Deus como Energia Cósmica. Esse predomínio foi mais evidente ainda em relação às estudantes da enfermagem. Apenas uma minoria de estudantes de medicina considerou Deus como uma invenção humana.

A visão acerca de espiritualidade é bastante variada, algumas vezes se confundindo com um conceito religioso, outras apontando mais para um sentido da vida, mas quase sempre relacionado à transcendência onde existe o que não é material ou mesmo lógico e objetivo. A maioria dos graduandos vinculou espiritualidade a questões existenciais do ser humano. Já ao início do curso, os participantes em geral demonstraram considerar importante a reflexão acerca de temas pertinentes à existência da alma, vida após a morte, milagres, relação da doença com a vida espiritual, influência da espiritualidade na vida profissional, o que os teria levado a escolher cursar uma disciplina com semelhante temática. Ao final da disciplina, essa percepção mostrou-se mais acentuada. Ainda, chamou a atenção o fato de que, em um grupo de estudantes universitários, um número não desprezível concordou com a influência de "feitiçarias" e "endemoniados" como forma de adoecer.

\section{Principais temas emergentes}

A análise dos textos compostos pelos estudantes conforme explicado na metodologia evidenciou os seguintes temas, os quais são ilustrados por frases dos estudantes:

A busca de sentido da vida. Em uma disciplina sobre Espiritualidade em que os discentes tiveram a oportunidade de discorrer livremente sobre suas ideias e opiniões surgiram várias concepções acerca de Deus. Alguns se declararam ateus e referiram não acreditar em nenhum tipo de Deus, não tendo, portanto, uma concepção formada. No outro extremo havia os que apresentavam uma concepção pessoal de Deus, como afirma uma estudante: “Deus se faz presente na vida daqueles que se permitem tal experiência e caminha junto dessas pessoas, tornando-as mais humanas."

Houve estudantes que apresentaram um conceito abstrato de Deus, considerando-o uma energia, uma força que rege o universo, uma entidade cósmica e universal que está presente em todas as coisas e pessoas. Outros consideraram Deus além de qualquer concepção humana. Assim, os textos e falas dos estudantes foram permeados por concepções acerca de um Deus imanente e, ao mesmo tempo, transcendente. “Acredito em Deus não como uma entidade definida, mas como algo de que todos fazemos parte e assim, 
teria influência em nossas vidas." "É uma força presente em cada ser vivo ou inanimado que está no mundo. Está em tudo que é bom e bonito."

Conteúdos relacionados às religiões também foram abordados, de forma natural e espontânea. Uma estudante de enfermagem escreveu:

Deus se faz presente pela revelação na Santíssima Trindade como o criador do mundo (Pai), como redentor dos homens (Filho) e como amor presente entre nós de maneira perene (Espírito Santo). Deus é, portanto, a origem, o caminho e o fim para o qual toda existência humana deve ser orientada.

A ideia de Deus como uma força que possa influenciar nossas vidas foi praticamente universal no grupo de estudantes que completaram a disciplina. “Com Deus tudo fica mais fácil. Deus ama a todos e com seu amor ele cura, faz milagres, liberta e alegra. Sentir o amor de Deus é maravilhoso. Creio nele, pois sei que ele sempre esteve participando da minha vida, me protegendo e me curando." Mesmo quem considera Deus uma criação humana reconheceu sua importância na vida humana: "Acredito que Deus seja uma criação das culturas e civilizações humanas, e que esta criação sempre representou uma ideia muito importante para os homens."

O conceito de espiritualidade foi desvinculado de religião e espiritualidade foi definida como uma busca pessoal do transcendente, um recurso capaz de atribuir sentido e significado às angústias e dilemas que permeiam a existência humana. "É a forma (não religiosa) de se lidar com as questões mais profundas da subjetividade de cada um. É a esfera que transcende o concreto e o objetivo", escreveu um estudante. Alguns discentes consideraram que a espiritualidade é inerente ao ser humano e permite lidar com aquilo que não pode ser visto e nem é palpável. Para alguns, a espiritualidade está ligada à fé: "Ser espiritual é ter fé, é acreditar em algo sem precisar de uma comprovação científica". Espiritualidade também foi relacionada a um conjunto de crenças pessoais, as quais incluem o entendimento de que a vida não acaba com a morte e que há algo além desta dimensão física.

Dentre todas as visões manifestadas acerca da espiritualidade, um ponto comum perpassava a todas e ficou evidente nos textos escritos pelos estudantes e em suas falas em sala de aula - a relação de espiritualidade e a busca de sentido da vida. A obra de Viktor Frankl, psiquiatra que estabeleceu uma escola de psicoterapia fundamentada em uma experiência pessoal profunda, ocorrida em seu período de permanência em campos de concentração nazistas, incluindo Auschwitz, mostra a importância da busca de sentido da vida, especialmente em situações de sofrimento, dor e morte, condições comuns no dia-a-dia dos estudantes e profissionais da saúde. Segundo Frankl, o sentido da vida é um dom e este nunca desaparece. Está fundamentado na vontade do sentido, ou seja, no desejo de descobrir sentido 
na existência humana e na liberdade da vontade, o que significa a liberdade para descobrir este sentido e escolher uma atitude diante do sofrimento. Para Frankl, o sentido da vida se centra na criatividade, na experiência e na atitude. Além disso, o pensador Frankl aponta para três problemas existenciais inevitáveis: o sofrimento, a morte e a culpa (Pessini, 2008).

Alguns dos componentes da espiritualidade admitidos por Ross (1995) também foram evocados pelos estudantes, tais como: necessidade de encontrar significado, razão e preenchimento na vida; necessidade de esperança e vontade para viver; necessidade de ter fé em si mesmo, nos outros e em Deus. A necessidade de significado é considerada uma condição essencial à vida e, quando um indivíduo se sente incapaz de encontrar um significado, sofre em função dos sentimentos de vazio e desespero. Estes componentes se vinculam a circunstâncias e situações extremamente frequentes, quer para o paciente, quer para o profissional de saúde.

Independência entre concepções acerca de Deus e espiritualidade e a importância atribuída ao curso. Com o avanço na leitura dos textos recomendados e o aprofundamento da reflexão promovida em sala de aula, os discentes foram consta-tando que, para a formação de um bom profissional de saúde, é necessário transcender o modelo biomecânico de ensino, questão que tem sido amplamente defendida por diversos autores em todo o mundo (Swick, 2000). O cuidado integral do paciente e de seus familiares requer que o ser humano seja considerado em sua totalidade, ou seja, em suas dimensões física, mental, emocional, cultural e espiritual, pois todas estas estão envolvidas no processo saúde-doença.

A análise dos textos dos discentes confirmou o resultado que havia sido sugerido pelas respostas às questões fechadas de que o curso Espiritualidade e Saúde é fundamental à formação profissional, pois oferece recursos que permitem ao futuro profissional de saúde transcender o modelo biomecânico e exercer sua função de acordo com as raízes históricas da medicina ou enfermagem, ou seja, ir além das medidas que visam a terapêutica e cura dos pacientes para incorporar um sentido mais amplo do cuidar. Neste sentido, a espiritualidade foi considerada por seu papel paliativo ou terapêutico, tendo sido valorizada sobremaneira nas condições em que a tecnologia não é mais capaz de oferecer soluções definitivas, como é o caso de pacientes em cuidados paliativos ou terminais.

Durante o curso de Espiritualidade e Medicina, percebi que nesses momentos em que todo mundo diz: 'eu não sei mais o que fazer', é porque justamente eles esqueceram de valorizar o que está além do orgânico. Não é fácil, mas também acho que os pacientes não esperam sacadas superinovadoras e criativas - eles querem empatia, um olhar cuidadoso, uma palavra de incentivo e conforto. Querem a humanidade, pois o corpo não está mais respondendo. Eles querem ainda alimentar o que ainda resta. E essa esperança está na esfera da espiritualidade. 
E o mais surpreendente foi constatar que essa opinião foi compartilhada pelos estudantes que se declararam ateus ou que não davam importância às questões referentes à espiritualidade em suas vidas. Um deles - estudante de medicina - declarou:

Não importam minhas crenças ou visão de vida, mas se quero propiciar um cuidado adequado a meus pacientes devo estar atento às suas totais necessidades, as quais, muitas vezes, dizem respeito a questões espirituais. O curso Espiritualidade e Saúde atraiu minha atenção para este ponto e foi essencial para minha formação.

Espiritualidade e humanização. Tem sido reconhecido o fato de que o ensino baseado exclusivamente no modelo biomecânico não responde aos anseios de estudantes e jovens profissionais da área de saúde no que diz respeito ao tema humanização em saúde. Por outro lado, as escolas médicas têm tido dificuldades em propiciar tal ensinamento e muitas vezes os estudantes e jovens médicos se sentem desamparados e sobrecarregados com a responsabilidade de adquirirem por si próprios, no dia-a-dia, a capacidade de propiciar um cuidado humanizado (Nogueira da Silva e Ayres, 2010). Os estudantes e jovens médicos referem que são alertados sobre a necessidade de evitar a desumanização, condição essa muitas vezes atribuída ao sistema, mas não sabem como fazer isso, conforme afirma um residente de medicina citado por Nogueira da Silva e Ayres (2010): “Eu queria não desumanizar, saber cuidar dos meus pacientes na doença e na morte. Como aprendo? Sozinho, no dia a dia?"

Durante o curso Espiritualidade e Saúde, os estudantes de medicina e enfermagem mostraram suas preocupações acerca da desumanização vigente nas práticas das ciências da saúde principalmente caracterizada por pacientes descontentes diante de profissionais que, talvez por falta de preparo, praticamente ignoram o sofrimento de seus pacientes. Muitos deles apresentaram esse questionamento: “Onde é que nos ensinam ou pretendem ensinar a sermos humanos com os pacientes. Que disciplina aborda ou deveria abordar isso?"

Tais anseios evidenciam que as questões relacionadas à humanização em saúde atingiram grandes dimensões, motivo pelo qual o tema tem sido contemplado nas reformas curriculares que vão sendo implantadas nacionalmente. Pesquisa realizada por Garcia, Ferreira e Ferronato (2012, p. 91) mostra a preocupação de alguns autores em considerar as "percepções e impressões dos discentes no que diz respeito às experiências que permitam o contato e um possível desenvolvimento de conteúdo, habilidades e comportamentos voltados à humanização" na implementação de atividades pedagógicas que fomentem a humanização. 
Os participantes da disciplina Espiritualidade e Saúde vincularam o conteúdo temático abordado à questão da humanização. Um estudante escreveu: "Se uma universidade se preocupa com uma educação médica mais humanizada, é imprescindível a abordagem da espiritualidade na graduação." Outra estudante complementou essa ideia: “Ter a consciência de que a espiritualidade é uma dimensão importante no tratamento do paciente já é um sinal de uma medicina mais humanizada, pois parte-se do pressuposto que o indivíduo é um todo e não simplesmente portador de uma patologia."

Os participantes da disciplina Espiritualidade e Saúde valorizaram seu potencial humanizador, dada a oportunidade de refletir acerca de questões existenciais que estão além da dimensão biológica do ser humano, pois essa reflexão é essencial para se lidar adequadamente com as situações em que a tecnologia não mais é capaz de prover soluções, como ilustra a seguinte afirmação:

Sempre posso fazer algo pelo paciente, mesmo aquele que não tenha mais possibilidades terapêuticas. Posso ouvi-lo, ficar ao seu lado e possibilitar que vivencie as crenças que possam lhe dar conforto. Nessas horas, a espiritualidade faz uma grande diferença e propiciar condições para que o paciente exerça sua espiritualidade deve ser parte de um atendimento mais humanizado.

A tríade de Frankl, que diz respeito a sofrimento, morte e culpa (Pessini, 2008), pôde ser observada na análise do trabalho de McCord (2004) em que se procurou avaliar se os pacientes gostariam ou não de serem abordados no aspecto da espiritualidade na dependência de determinadas situações que se encontrassem. Verificou-se que, frente a doenças graves e proximidade da morte, mais de $90 \%$ dos pacientes sentem uma necessidade de ser abordados na esfera da espiritualidade. Mesmo em situações não graves, como a visita inicial, $43 \%$ de todos os entrevistados acharam importante a abordagem do assunto. Por outro lado, é visível que as situações que envolvem comportamento violento, abuso sexual e sofrimento crônico nos reportam obrigatoriamente a refletir sobre os aspectos éticos (bioéticos) que estão incluídos nestas ocorrências (McCord et al., 2004; Peres, 2007). O reconhecimento das crenças dos pacientes e da forma como vivenciam sua espiritualidade é uma dimensão importante no tratamento do paciente e por si só é sinal da prática de uma medicina mais humanizada. Abrir um canal para comunicação com pacientes e familiares permite que se reconheça suas reais necessidades, as quais costumam ir bem além do que a mera prescrição de medicamentos e medidas que visem a prevenção e supressão de sintomas. Prestar atenção a essas necessidades não apenas é parte importante de um cuidado holístico e humanizado como também melhora os resultados clínicos. Uma aluna de medicina relatou: 
Ao longo do curso Espiritualidade e Saúde percebi-me com uma nova capacidade como estudante e futura profissional da área da saúde. Pela liga de Clínica Médica, atendo a pacientes com doenças crônicas e faço seu acompanhamento. Ao final de cada consulta, passo o caso para o preceptor, um clínico que indica a conduta a ser tomada e recomendo algumas orientações. Assim, inspirada pelo curso, resolvi incluir em minhas orientações uma abordagem mais espiritual e o resultado foi que os pacientes voltaram com menos queixas referentes ao período interconsulta e se apresentaram em melhor estado geral. Isso aconteceu mesmo naqueles pacientes em que as condutas anteriores foram mantidas. A espiritualidade não é apenas um instrumento humanizador, mas também representa uma importante ferramenta terapêutica, e deve ser muito utilizada pelo médico que a conheça com habilidade.

Considerou-se que o resgate de uma medicina que valoriza o ser humano deve ser realizado na graduação, para que o encanto dos novos conhecimentos biológicos não ofusque a sensibilidade e a empatia, qualidades que, com ou sem tecnologia, têm se mostrado essenciais a um bom profissional da área de saúde.

Espiritualidade, cuidado de si e busca do autoconhecimento. Inúmeros fatores geradores de angústia têm sido identificados entre alunos da área de saúde e o enfoque inadequado a essa questão resulta em uma estratégia de defesa que consiste na negação das emoções. Tal atitude é extremamente desumanizadora, pois se os estudantes não lidam adequadamente com as próprias emoções, como o farão em relação aos pacientes? Os componentes emocionais que o contato com a dor, o sofrimento e a morte geram no estudante deveriam ser contemplados durante os anos de graduação. Além do suporte psicológico oferecido pelos serviços de apoio ao estudante presente em várias universidades, também tem sido sugerida a implementação de atividades de tutoria e ensino em pequenos grupos como forma de favorecer a emergência das emoções e possibilitar a reflexão (Quintana et al., 2008).

Os estudantes entram em uma faculdade de medicina ou enfermagem motivados por um ideal que vai se esfacelando aos poucos. Há estudos que mostram a erosão da empatia que ocorre ao longo do curso de medicina, pois, sem um suporte adequado, o mais cômodo é não se envolver e ignorar a dor e o sofrimento dos pacientes (Hojat, 2009). A disciplina Espiritualidade e Saúde possibilitou o estabelecimento de um ambiente propício à clarificação de emoções e sentimentos desconfortáveis.

Para que o médico consiga acompanhar devidamente seus pacientes em sofrimento de um modo seguro, sensível, tranquilo e com compaixão, ele deve ser muito bem preparado. É inegável que o exercício da medicina de tal modo requer mais esforço e envolvimento, mas isso é que deve ser a medicina de verdade. 
Essa questão foi reconhecida pelos estudantes durante a disciplina Espiritualidade e Saúde, como escreveu uma aluna:

Durante a faculdade de medicina poucas ocasiões nos fazem refletir tanto a respeito de questões existenciais e aspectos não biológicos do ser humano. E essa reflexão é de extrema importância para nós, porque nos faz entender a nós mesmos e, só assim, estaremos preparados para atender ao paciente.

A ideia de que estudar espiritualidade em ciências da saúde deveria interessar apenas aos que têm uma espiritualidade fortemente presente em sua vida foi se modificando ao longo do curso. Houve quem fizesse importantes descobertas existenciais:

Foi como se eu tivesse feito uma descoberta existencial de grande importância em minha vida, a qual me deu certo alívio. (...) Passei a pensar que só me sinto realmente viva, ou seja, só sinto que sou um ser humano com existência nesse mundo um tanto quanto caótico, quando consigo transcender o concreto, quando consigo perceber que sou dotada de algo muito complexo, e talvez desconhecido, que as pessoas intitularam de alma.

O estudo da espiritualidade abre perspectivas para o cuidado de si e autoconhecimento, condições essenciais para a formação de um profissional. Monteiro (2008) refere que Jung já atribuía importância aos valores e crenças do profissional, pois, segundo ele, querendo ou não, o profissional está envolvido com suas convicções, tanto quanto o paciente, e o mais importante não é a 'técnica utilizada', mas a pessoa que usa determinado método. Por isso, o profissional estaria, eticamente, obrigado a um conhecimento e a uma crítica de suas convicções pessoais, filosóficas e religiosas, tanto quanto um cirurgião está obrigado a uma perfeita assepsia.

\section{Conclusão}

A separação entre o corpo e o espírito, promovida principalmente pelo acelerado progresso científico-tecnológico, ocasionou um empobrecimento na avaliação do paciente na globalidade integrativa das suas dimensões biológicas, psicológicas, sociais e espirituais. Se, por um lado, os recursos tecnológicos, cada vez mais sofisticados, ampliaram a nossa capacidade de penetrar no universo molecular da constituição humana, por outro, eles promoveram uma diminuição da sensibilização em relação aos sentimentos humanos, o que, certamente, resultou em uma deterioração da imprescindível relação profissional da saúde-paciente. 
No interior dos sentidos e dos sentimentos esconde-se a transcendência da natureza humana, manifesta na sua espiritualidade que pode se concretizar em ritos e devoções de uma crença religiosa. Esta influência no processo saúde-doença não deveria ficar à margem do estudante que se prepara para uma visão holística na assistência do seu futuro paciente. Ao paciente, esta percepção não foi retirada pela história do avanço tecnológico, assim como ainda não o foi ao jovem estudante quando este é apresentado, nos primeiros anos de estudo, a uma prática fundamentada no modelo tecnicista.

Esta experiência didática com os estudantes veio reforçar que, para um preparo adequado do aluno que se dirige à área da saúde, o campo da espiritualidade não pode ser avaliado como curiosidade ou uma possibilidade, mas uma exigência necessária declarada pelos próprios estudantes. Exigência requerida não somente para a formação profissional, mas também para a formação pessoal do aluno. A inserção de uma disciplina que colabore nesta formação poderá favorecer o desenvolvimento de futuros profissionais, os quais estejam mais atentos e aptos a acolher e a compreender as necessidades espirituais do paciente no seu processo saúde-doença, como um recurso a ser utilizado na melhora da qualidade do seu acompanhamento, oferecendo uma proposta concreta de solução às queixas frequentes da desumanização do sistema de saúde. Essas afirmações se baseiam principalmente nas manifestações da maioria dos graduandos em sua avaliação da disciplina Espiritualidade e Saúde.

\section{Colaboradores}

Os autores colaboraram igualmente em todas as etapas da preparação do manuscrito. Não há conflito de interesses. 
Resumen Encuestas demuestran que, aun hoy, la espiritualidad representa un aspecto importante en la vida humana. Las conquistas del modelo biomecánico de enseñanza y práctica de la medicina no han logrado ofuscar el papel que la espiritualidad ocupa en el proceso salud-enfermedad. Siguiendo una tendencia que se registra en las escuelas médicas de todo el mundo, los autores introdujeron, en la Universidad Federal de São Paulo, la disciplina electiva - Espiritualidad y Medicina - dirigida a estudiantes de medicina y enfermería, con el objetivo de fomentar el reconocimiento de la dimensión espiritual del paciente y, en consecuencia, una atención más humanizada. Después de cuatro años de curso, se procedió a un estudio cualitativo para determinar el perfil de los estudiantes que seleccionaron la disciplina electiva, su percepción con relación al tema espiritualidad y salud, y la importancia atribuida al curso en lo que concierne a su formación personal, profesional y humanística. Los textos producidos por los alumnos durante el curso constituyeron la principal fuente de datos. La interpretación de los datos se realizó mediante un enfoque de la fenomenología hermenéutica y puso de manifiesto los siguientes temas: búsqueda de sentido de la vida; independencia entre concepciones acerca de Dios y espiritualidad y la importancia atribuida a la disciplina; espiritualidad y humanización; y espiritualidad, cuidado de sí y autoconocimiento.

Palabras clave espiritualidad y salud; educación en salud; humanización.

\section{Notas}

1 Universidade Federal de São Paulo, Escola Paulista de Medicina, Centro de História e Filosofia das Ciências da Saúde, São Paulo, SP, Brasil.

<vreginato@uol.com.br>

Correspondência: Rua Botucatu, 720, Vila Clementino, CEP 04023-900, São Paulo, SP, Brasil.

2 Universidade Federal de São Paulo, Escola Paulista de Medicina, Centro de História e Filosofia das Ciências da Saúde, São Paulo, SP, Brasil.

$<$ macbet@sobramfa.com.br>

3 Universidade Federal de São Paulo, Escola Paulista de Medicina, Centro de História e Filosofia das Ciências da Saúde, São Paulo, SP, Brasil.

<dante.cehfi@epm.br> 


\section{Referências}

AYRES, José R. C. M. Hermenêutica e humanização das práticas de saúde. Ciência \& Saúde Coletiva, Rio de Janeiro, v. 10, n. 3, p. 549-60, 2005.

BORKAN, Jeffrey. Immersion/Crystallization. In: MILLER, William L.; CRABTREE, Benjamin F. Doing Qualitative Research. 2 ed. Thousand Oaks: Sage Publications, 1999, p. 179-194.

BOYD, Carolyn O. Qualitative approaches to research. In: WOOD, LoBiondo; HABER, Judith. Nursing research: Methods, critical appraisal and utilization. 3. ed. St. Louis: Mosby-Year Book, 1990.

DE MARCO, Mario A. A face humana da medicina: do modelo biomédico ao modelo biopsicossocial. São Paulo: Casa do Psicólogo, 2003.

DRANE, James; PESSINI, Leo. Bioética, medicina e tecnologia: desafios éticos na fronteira do conhecimento humano. São Paulo: Edições Loyola, 2005.

GALLIAN, Dante M. C. A (Re)humanização da medicina. Psiquiatria na Prática Médica, São Paulo, v. 33, n. 2, p. 5-8, 2000.

GALLIAN, Dante M. C.; REGINATO, Valdir. Relação assistencial e sua humanização. In: RAMOS, Dalton L. P. (org.). Bioética: pessoa e vida. 1. ed. São Caetano do Sul: Difusão Editora, 2009, p. 117-133.

GARCIA, Maria A. A.; FERREIRA, Fernanda P.; FERRONATO; Fernanda A. Experiências de humanização por humanização de medicina. Trabalho, Educação e Saúde, Rio de Janeiro, v. 10, n. 1, p. 87-106, 2012.

GUIMARÃES, Helio P.; AVEZUM, Álvaro. O impacto da espiritualidade na saúde física. Revista de Psiquiatria Clínica, São Paulo, v. 34, s. 1, p. 88-94, 2007.

HOJAT, Mohammadreza et al. The devil is in the third year: a longitudinal study of erosion of empathy in medical school. Academic Medicine, Washington DC, v. 84, p. 1182-1191, 2009.

KOENIG, Harold G. Espiritualidade no cuidado com o paciente. São Paulo: Fé Editora Jornalística, 2005.

KUZEL, Anton. J Sampling in qualitative inquiry. In: MILLER, William L; CRABTREE, Benjamin. F. Doing Qualitative Research. 2 ed. Thousand Oaks: Sage Publications, 1999.

LARIMORE, Walter L. Medicine and society: providing basic spiritual care patients: should it be the exclusive domain of pastoral professionals? American Family Physician, Kansas City, v. 3, n. 1, p.81-84, 2001.

LOPES, Otacílio C. A medicina no tempo. São Paulo: Edições Melhoramentos e Editora da Universidade de São Paulo, 1970.

McCORD, Gary et al. Discussing spirituality with patients: a rational and ethical approach. Annals of Family Medicine, Cleveland, v. 2, n. 4, p. 356-361, 2004.

MONTEIRO, Dulcinéia M. R. Espiritualidade e saúde na sociedade do espetáculo. In: PISSINI, Léo; BACHIFONTAINE, Christian (orgs.). Buscar sentido e plenitude de vida: bioética, saúde e espiritualidade. 1. ed. São Paulo: Paulinas, 2008. p. 63-86.

NIGHTINGALE, David J.; CROMBY, John. Social constructionist psychology. Buckingham: Open University Press; 1999.

NOGUEIRA DA SILVA, Geórgia S.; AYRES, José R. C. M. O encontro com a morte: à procura do mestre Quíron na formação médica. Revista Brasileira de Educação Médica, Rio de Janeiro, v. 34, n. 4, p. 487-496, 2010 .

OSLER, William. The faith that heals. British Medical Journal, London, June 18, 1910, p. $1.470-1.472$. 
PERES, Mario et al. A importância da integração da espiritualidade e da religiosidade no manejo da dor e dos cuidados paliativos. Revista de Psiquiatria Clínica, São Paulo, v. 34, n. 1, 82-87, 2007.

PESSINI, Leo. A espiritualidade interpretada pelas ciências e pela saúde. In: PESSINI, Leo; BARCHIFONTAINE, Christian P. (org.). Buscar sentido e plenitude de vida: bioética, saúde e espiritualidade. São Paulo: Paulinas, 2008, p. 45-62.

PINTO, Cândida; PAIS-RIBEIRO, José L. Construção de uma escala de avaliação da espiritualidade em contextos de saúde. ArquiMed, Porto, v. 21, n. 2, p. 47-53, 2007.

PUCHALSKI, Christina M. The hole of spirituality in health care. BUMC Proceedings, Waco, v. 14, n. 4, p. 352-357, 2001.

QUINTANA, Alberto M. et al. A angústia na formação do estudante de medicina. Revista Brasileira de Educação Médica, Rio de Janeiro, v. 32, n. 1, p. 7-14, 2008.

REALE, Giovanni. História da Filosofia. v. III. São Paulo: Paulinas, 1991.

ROSS, Linda. The spiritual dimension: its importance to patients' health, well-being and quality of life and its implications for nursing practice. International Journal of Nursing Studies, London, v. 32, n. 5, p. 457-468, 1995.
SAAD, Marcelo; MASIERO, Danilo; BATTISTELLA, Linamara R. Espiritualidade baseada em evidências. Acta Fisiátrica, São Paulo, v. 8, n. 3, 2001.

SALGUEIRO, Jennifer B.; GOLDIM, José R. As múltiplas interfaces da bioética com a religião e espiritualidade. In: GOLDIM, José R. (org.) et al. Bioética e Espiritualidade. Porto Alegre: EDIPUCRS, 2007, p. 11-28.

SAVIOLI, Roque M. Fronteiras da ciência e da fé. São Paulo: Editora Gaia, 2006.

SWICK, Herbert. Toward a normative definition of medical professionalism. Academic Medicine, Washington DC, v. 75, n. 6, p. 612-616, 2000 .

VOLCAN, Sandra M. A. et al. Relação entre bem-estar espiritual e transtornos psiquiátricos menores: estudo transversal. Revista de Saúde Pública, São Paulo, v. 37, n. 4, p. 440-445, 2003.

YAWAR, Athar. Spirituality in medicine: what is to be done? Journal of Royal Society of Medicine, London, v. 94, n. 10, p. 529-533, 2001.

Recebido em 25/07/2012

Aprovado em 04/03/2015 